\title{
Natural Rhythmic Patterns in English Verse: Evidence from Child Counting-Out Rhymes
}

\author{
Michael H. Kelly \\ University of Pennsylvania
}

AND

\author{
David C. Rubin
}

\section{Duke University}

\begin{abstract}
Counting-out rhymes are part of an oral tradition whose primary participants are children. These facts are used to justify the claim that the rhythmic structure of counting-out rhymes can be attributed to natural preferences more readily than could the structure of formal verse considered alone. The first study uncovered a number of similarities between formal and counting-out verse. The rhythm of counting-out rhymes is constrained by the principle of rhythmic alternation, the nuclear stress and compound rules, and foot boundaries. In addition, both trochaic and iambic meters seem to exist as natural categories in counting-out rhymes. Finally, children appear to associate different grammatical categories with different degrees of stress, in a manner very similar to patterns found in adult verse. The second study explored the variants of one common counting-out rhyme and reports changes that preserve or improve the poetics of the rhyme. The discussion offers one definition of what a "natural" rhythmic pattern in verse might mean: A pattern that has parallels in the rhythmic structure of ordinary speech. This definition makes the study of verse attractive to psycholinguists for three reasons. First, factors that influence speech rhythm can be examined for their relevance to poetic rhythm, a possibility that renders tractable the psycholinguistic study of one form of language creativity. Second, hypotheses about the rhythmic structure of speech can be formulated from knowledge of poetic rhythm. Finally, studying the structure of child verse could foster understanding of the acquisition of prosodic rules, an area that has been relatively neglected in developmental psycholinguistics. 1988 Academic Press, Inc.
\end{abstract}

One of the most oft-disputed questions in art criticism is the extent to which the structure of artwork reflects arbitrary, culturally defined conventions or patterns naturally preferred as a normal consequence of hu-

We thank Dorritt Billman, Kay Bock, Patricia Carpenter, Lila Gleitman, and two anonymous reviewers for helpful comments on previous drafts of this manuscript. This paper was supported by an NIH Biomedical Research Support Grant and NIH Grant 1 R29 HD233385-01 to Michael Kelly, and by NSF Grant BNS-8410124 to David Rubin. Correspondence concerning this article may be addressed to Michael Kelly, Department of Psychology, University of Pennsylvania, 3815 Walnut Street, Philadelphia, PA 191046196. man cognitive and perceptual systems (Arnheim, 1974; Gombrich, 1961). In the area of poetic metrics, this question specifically focuses on the rules governing the rhythmic structure of verse. Recent linguistic investigations have shown the rhythmic structure of verse penned by English poets such as Shakespeare, Milton, and Pope to be governed by a number of subtle rules that had been undetected by prosodists until quite recently (Kiparsky 1975, 1977). The very subtlety of these rules suggests that English poets could not have been consciously following them, and so they may reflect natural rhythmic preferences in English rather than arbitrary conventions as- 
sociated with particular poetic traditions. Further evidence for this claim derives from the fact that many of these rules apply to normal conversational speech. Hence, certain rhythmic patterns of verse must be naturally preferred since they appear in "nature," where the latter is defined as typical spoken interchange. Nonetheless, such conclusions must be questioned because of the fact that human beings follow unconsciously many rules that have their foundations in cultural tradition. Formal English poets clearly wrote within certain poetic traditions, and many of the rhythmic rules associated with these traditions may have been learned and followed unconsciously by these poets. In addition, although some of the conditions governing verse rhythm operate also in normal speech, others do not or, at least, have not as yet been shown to be relevant. Such patterns therefore may derive from arbitrary convention. Finally, any natural preference in conflict with a poetic tradition could be effectively masked because of the reliance on writing rather than memory as a means of preserving one's verse.

Evaluating the natural versus arbitrary nature of rhythmic rules in English poetry could be performed more securely by analyzing verse forms that (1) do not rely on external memory aids to preserve naturally "bad" patterns and (2) are used by people not yet indoctrinated in English poetic traditions. In this paper, we will compare the rhythmic structure of formal English verse with that of a verse form that possesses these and other favorable characteristics. This verse form consists of the jingles that children use to determine who is "it" in games such as hide-and-seek, kick-the-can, and poison. These verses exist in a wide variety of cultures and generally take the form of nonsensical incantations recited by a child leader (Bolton, 1988). With each main stress in the verse, the speaker points to a different child in the group. The child upon whom the last stress of the chant falls is magically relieved of the possibility of being "it." The chant is then recited again and again until all but one of the children are "out." In one of childhood's earliest performative utterances, the remaining child is dubbed "it," and the game begins. Because these chants involve a type of counting, often quite explicitly as in the very popular

(1) One potato, two potato, three potato, four,

Five potato, six potato, seven potato, more, 1

they are typically called "counting-out rhymes."

Counting-out rhymes have several major advantages for the study of poetic rhythm. First, counting-out rhymes are a true oral tradition with little contamination from the memory aid of writing. Because of this fact, any rhyme that exists for a period of time, and some have existed for the century that folklorists have been recording the genre, must be structured so that they can be learned, remembered, and retold with relative ease. Rhythmic patterns that were not easy to learn (or were not aesthetically pleasing) would have many opportunities to be lost or changed into better ones. Memory distortions that create or maintain good form are common in the recreation of stories (Bartlett, 1932), perceptual figures (Köhler, 1947), and have even been observed in counting-out rhymes (Rubin, 1986). For instance, transformations of counting-out rhymes tend to preserve poetic structure. Thus variants of "eenie, meenie, miney, mo" preserve the rhythmic pattern and alliteration of the line. Historical variants include "eena, deena, dina, do" but not "eenie, meenie, diney, mo." In addition, as illustrated by (2), a good deal of counting-out verse lacks any coherent semantic structure that could aid their recall. Thus, unlike formal English verse or se-

\footnotetext{
${ }^{1}$ All counting-out rhymes quoted in the paper are drawn from Abrahams and Rankin (1980).
} 
mantically rich oral poetry such as that sung in Yugoslavia (Lord, 1960), memory for counting-out rhymes depends almost entirely on poetics, such as rhyme, alliteration, and rhythm:

(2) Eena, meeny, dippery Dick, Deelia, dollia, Dominick, Hypa, potcha, dominotcha, Tee, taw, tick.

Second, unlike most other genres, counting-out rhymes are defined by function, not form. Thus, our corpus is based on Abrahams and Rankin's Counting-Out Rhymes: A Dictionary (1980), which consists of sayings that children use to decide who is "it." Folklorists did not exclude poetic patterns because they lacked a particular predefined structure, such as a certain rhyme scheme or pattern of alliteration. The only criterion for inclusion was a functional one, and therefore the rhythmic patterns reported here are not an artifact of a structurally defined genre.

Third, although defined by function, counting-out rhymes are a genre when examined in terms of form. To demonstrate this claim, the 24 most cited counting-out rhymes in the Abrahams and Rankin dictionary were compared with a randomly selected sample of 24 rhymes that were cited only once. The most popular rhymes represent most of the actual usage in English over the last century. The rare rhymes offer a good chance to see if rhymes noticed only once by folklorists, and perhaps even created and used in only one place and at only one time period, follow the conventions of the common rhymes.

The common rhymes and rare rhymes did not differ in average number of lines, with common rhymes containing an average of 4.6 lines and rare rhymes containing an average of 4.1 lines. The average proportion of words repeating, rhyming, alliterating, showing assonance with another word, or involved in at least one of these poetic devices for the common vs rare rhymes are .19 vs $.14, .24$ vs $.21, .25$ vs .21 ,
.25 vs .26 , and .87 vs .82 , respectively (all $t(46)<1.30$, nonsignificant). There was a difference in the proportion of 4-beat lines between the common and rare rhymes, .83 vs $.60(t(46)=2.05, p<.05)$, though the 4-beat rhyme was, by far, the most common pattern in both samples. More subtly, the placement of the beats was better poetically in the common rhymes. Thus, more of the words involved in repetition, rhyme, alliteration, or assonance fell on strong beats in the common rhymes than in the rare rhymes (.90 vs .79 , respectively, $t(46)$ $=2.53)$. Thus, the common and rare rhymes appear to be quite similar, with the common rhymes showing a better fit of the repetition of sound pattern to the rhythmic structure, which may explain their greater popularity.

Finally, and most importantly, the participants in the counting-out tradition are almost exclusively children. The rhymes are therefore passed on from child to child rather than adult to child (Opie \& Opie, 1959). Since the children are not educated as yet in the traditions of formal English poetry, the rhythmic structure of their verse stands a better chance of reflecting inherently natural rhythmic patterns. One could argue that the counting-out rhymes originated with adults, and were only later confiscated by children. Thus, the poetics in such verse may reflect the preferences of more poetically sophisticated parents rather than those of their children. Although many rhymes used by children do derive from verse present in the adult community, children subsequently invent variations of these rhymes on their own and pass them on to their peers. Thus, around the time of the Abdication in 1936, a popular rhyme among British children was "Hark the herald angels sing/Mrs. Simpson pinched our king." Even though the jingle derives from a Christmas carol known in the adult community, the modification was doubtfully invented by adults and was observed only in school children (Opie \& Opie, 1959). Since the modifications must 
later be remembered by children, their structure should reflect to some extent the poetic patterns that aid memory. In addition, even if children learn some specific rhymes from adults, the large numbers of existing rhymes and influx of new variants suggest that children are using a productive system, rather than a few rigid forms. In other words, although children learn their particular language from hearing specific adult utterances, what they acquire is an abstract system of rules rather than the utterances themselves. By analogy, the generation of new counting-out variants by children is evidence that they are acquiring abstract rules of prosody, and it is the acquisition of these rules that is the focus of language development study.

Of course, this last point assumes that children do invent some counting-out rhymes. One final test designed to determine whether counting-out rhymes are somewhat insulated from adult influence draws upon results from standard psycholinguistic experimentation. In particular, Seidenberg and Tannenhaus (1979) found that adult listeners were faster at determining whether two words rhyme if the words had similar orthographies. For example, subjects were faster at classifying " $t i e$ " and "pie" as rhymes compared with "tie" and "guy," even though the words were presented auditorily. Such results suggest that spoken words automatically prime orthographically similar words as well as phonologically similar words. If such effects influence a poet's choice of rhyme words, one would predict rhymes in formal verse to share orthography more than would be predicted by chance. However, since the child participants in the counting-out traditions are at best beginning readers, one might not expect to see orthographic effects on rhyme selection. If, on the other hand, counting-out rhymes are influenced by adults, the rhyme words in counting-out verse should show orthographic similarities. Details of this analysis are presented in Appendix A. The results found evidence of orthographic similarity among rhymes in formal verse, but no orthographic relation among rhymes in counting-out verse. These results indicate that counting-out rhymes were to some extent created by children with little influence from adults.

In sum, counting-out rhymes possess a number of characteristics that make them a good source for investigations of poetic rhythm. Most importantly, they represent an oral poetic tradition whose participants are almost exclusively children. In the first of two studies, we will analyze the rhythmic structure of counting-out verse in terms of rules known to operate in formal English poetry. The structure of these childhood chants, and their similarity to adult poetry, may reveal underlying metrical principles that organize English verse at many levels of sophistication. In terms of developmental psychology, the complexity of countingout rhymes may show children to be remarkably facile poets who possess, at a young age, complex metrical rules and keen sensitivity to poetic structure. In addition, and of more concrete theoretical importance for psychologists, analyses of counting-out rhymes provide a useful methodology for studying the child's acquisition of prosodic rules. Research and theory in language acquisition have focused on syntax, semantics, and word-level phonology, while generally ignoring prosodic development. $^{2}$ Thus, there is absolutely no data on the development of some of the most basic and well-documented rules of phraselevel stress in English. One might claim that the most obvious way to fill this gap would involve acoustic analyses of child speech rather than analyses of verse. However, as Levelt (in press) has pointed out, exclusive reliance on our technology for analyzing speech could be misleading since it as-

\footnotetext{
${ }^{2}$ This criticism applies to developmental investigations of language production rather than comprehension. A number of recent studies have examined infant and child sensitivity to prosody, and its use in detecting, for example, the clause boundaries in speech (e.g., Hirsh-Pasek et al., 1987).
} 
sumes a complete understanding of the acoustic correlates of stress and how they interact. Our understanding of these variables is still incomplete, and so we should be prepared to use other types of material when exploring prosody and prosodic development. Analyses of verse offer one supplementary way of examining child prosody because stress is defined in terms of the location of a syllable in a line, an operational definition that has worked well in analyses of formal verse (e.g., Halle \& Keyser, 1971).

\section{Study 1: The Rhythmic Structure of Counting-OUt Verse}

The purpose of this study is to determine whether metrical principles known to organize formal English verse also operate in counting-out verse. Because of the characteristics of counting-out rhymes discussed in the introduction, any similarities between these two domains may reflect basic principles of English rhythm. For example, in traditional poetic scansion, the monosyllabic words in phrases like "rich men" would both be considered stressed. However, the relative stress placed on these two words differs, with "men" receiving a slightly stronger accent. This pattern derives from the nuclear stress rule, which places primary stress on the rightmost constituent of a phrase (Chomsky \& Halle, 1968; Selkirk, 1984). If poets base the rhythmic structure of verse on the rhythmic structure of ordinary speech, then they should tend to align words such as "rich" in expected weak positions in their verse and words such as "men" in expected strong positions. Indeed, Kiparsky (1975) has confirmed such predictions in the verse of a variety of English poets, including Shakespeare, Milton, and Pope. (See below for further details.) If children are also sensitive to the stress differences created by the nuclear stress rule, then similar patterns should be found in counting-out verse.

Of course, in order to test this and other hypotheses described below, one must de- termine the expected weak and strong positions in counting-out rhymes. This task is more difficult than determining similar positions in the work of Shakespeare and Milton since one cannot refer to an established poetic tradition with known metrical rules in the case of counting-out verse. Thus we know that the choice of the sonnet form constrained Shakespeare to select iambic pentameter as the underlying meter of his lines, and so we know that the odd syllables in his verse map onto canonical weak positions whereas the even syllables map onto canonical strong positions. In the case of counting-out rhymes, on the other hand, we must induce the underlying metrical pattern of the line based solely on the distribution of weak and strong syllables found on the "surface." The means of scansion and the rules used to make these inferences will be described in the Methods section. For ease of exposition, the set of comparisons made between formal and counting-out verse will be described in the Results section.

\section{Method}

Our sample was drawn from Abrahams and Rankin's Counting-Out Rhymes: $A$ Dictionary (1980), which lists all citations to counting-out rhymes found in an extensive search of folklore and popular literature. The citations are from all over the English speaking world and date back to the mid-nineteenth century. The individual variants were categorized into 582 distinct rhymes, with the categorizations made, of course, without knowledge of the purpose of our analyses. Approximately 350 of the 582 rhymes are cited only once. Although we weighed common and rare rhymes equally, our conclusions are probably not jeopardized by this practice. As noted above, common and rare rhymes do not differ on a variety of measures, and differences that do emerge indicate that the common rhymes are better poetically. Thus, if even rare rhymes display consistent rhythmic structures then our claims will be true of the genre as a whole. Later, the most 
frequently cited rhyme will be analyzed in detail to ensure that the results hold for actual usage as well as for the genre as a literary entity.

Because of the large number of lines cited by Abrahams and Rankin and the variability in the lengths of the lines, our sample was restricted to all lines containing eight syllables. This criterion seemed reasonable given the frequency and crosscultural prevalence of octosyllabic lines in child verse (Burling, 1966), which suggest that they stand a good chance of being the metrical form most preferred by children, or at least a form that is quite central. In addition, as lines with fewer and fewer syllables are used, confidence in the ability to determine the underlying metrical structure of a line from its "surface" structure decreases. Unlike our source dictionary, therefore, we did use a structural criterion for including lines in our analysis. However, this criterion is quite weak, especially when compared with the many structural criteria used to define various types of formal verse. Nonetheless, when we analyze the structure of the most common countingout rhyme, all lines will be included regardless of length.

Each line was divided into four disyllabic feet. The syllables in each foot were then scanned using a simple stressed-unstressed dichotomy. This procedure could therefore result in four different types of foot: iambic (weak syllable and strong syllable), trochaic (strong-weak), spondee (strongstrong), and pyrrhic (weak-weak). A standard criterion was used to determine whether a syllable should be stressed or unstressed. Monosyllabic words were classified as stressed if they belonged to one of the major lexical categories (noun, verb, adjective, or adverb). All other monosyllabic words (determiners, pronouns, prepositions, contractible auxiliary verbs) were classified as unstressed. The normal contraction of words from such minor categories indicates their unstressed status. Only two deviations from these criteria were per- mitted. The first concerned the adverb not and the copula is. The frequent contraction of these words suggests that they are typically unstressed, and they were counted as such. The second concerned modal words like could, must, and might, and wh words such as who and what. These words were considered stressed for two reasons. First, many are not contractible, a property that is correlated with the presence of stress (Selkirk, 1984). Second, modals are acquired earlier than verbal auxiliaries (Brown, 1973). Since words that children acquire early tend to receive more stress in adult speech than words acquired later (Gleitman \& Wanner, 1982; Miller \& Ervin, 1964), this earlier acquisition suggests that modals are more stressed in speech than are auxiliaries.

The intonations of polysyllabic words were determined from their preferred citation stress patterns, if available, as given in Webster's New Collegiate Dictionary (1977). For the many nonsense words like eeny, mona, and jictum, stress was determined by the intuitions of the first author. A second person determined the stress patterns for the first 150 nonsense words listed in the sample. These words were presented out of their original lines, but the rater still agreed with the author in $96 \%$ of the words. Only the primary stress location was counted as a stressed syllable; all secondary and tertiary stresses were considered unstressed. Although this procedure for determining stress is not perfect, it generally led to interpretable patterns. Thus, the line "Eeny meeny figgledy fig" was scanned as

\section{(3) $\begin{array}{llll}\mathrm{SW} & \mathrm{SW} & \mathrm{SW} & \mathrm{WS}^{3}\end{array}$ Eeny / meeny / figgle- / dy fig.}

Although the final syllable in "figgledy" possesses a slightly stronger stress than the second syllable, it was classed as un-

\footnotetext{
${ }^{3}$ Stress marks (S or $\mathrm{W}$ ) placed above the line represent the line's actual scansion. Stress marks placed below the line represent the abstract metrical pattern on which the line is based.
} 
stressed. Nonetheless, this scansion produces an iamb in the final foot, which corresponds to the intuitive rhythm of the line. This scansion system is admittedly not the most sophisticated possible, and expert judges (whether adult or child!) might disagree with some of the readings. However, the system is simple, easy to replicate, and, most importantly, produces interpretable results.

Each scanned line was next classified as iambic, trochaic, or other depending on the relative number of iambs and trochees. Lines with more iambs than trochees were classified as iambic; lines with more trochees than iambs were classified as trochaic; and lines with an equal number of trochees and iambs were classified as other. These classifications may seem somewhat arbitrary, given the fact that one does not know whether such lines are truly iambic or trochaic. Perhaps the lines considered trochaic are actually iambic, but with their initial unstressed syllable deleted. Such lines are common in English verse, yet they are recognized correctly because of other information indicating the poem's underlying rhythmic structure. The main justification for the iambic and trochaic classifications of the counting-out rhymes is that the lines in the two classes show systematic differences, and these differences resemble those found for known iambic and trochaic lines. Such differences will be discussed below. The sample consisted of 246 trochaic lines, 157 iambic lines, and 30 " other" lines, for a grand total of 433 lines.

\section{Results}

Many of the lines selected from the counting-out rhymes are purely trochaic or iambic. For instance, the scanning techniques judged each foot in "Eeny meeny dixie deeny" and "See the monkeys chew tobacco" as trochaic. On the other hand, each foot in "He struck a rock, the clumsy clot" was classified as iambic. These results agree with the perceived rhythm of the lines. As with lines from Shakespeare, Milton, and Pope, however, some counting-out rhymes are primarily iambic or trochaic, but with certain deviations, as in

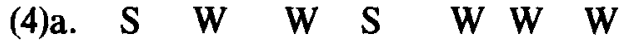 Play with / the gyp- / sies in / the S wood.}

\section{b. SW SW SW W S Eenty / teenty / heather- / y bell.}

Line $4 a$ is primarily iambic, with iambs present in the second and fourth foot. However, the first foot is clearly a trochee, and the third has a pyrrhic character. Line $4 b$, on the other hand, is primarily trochaic, with trochees occupying the first three feet. However, the final foot deviates from the consistent trochaic pattern, as the line closes with an iamb. An initial analysis of the lines in the sample reveal a large number of such deviations, but as in other forms of English verse, certain deviations are more common than others. These differences in the frequencies with which certain rhythmic deviations appear can give us insights into the types of rules that organize the rhythmic structure of counting-out rhymes. The discussion of such rules will be arranged around rules known to constrain the rhythmic structure of other forms of English verse.

The nuclear stress and compound rules. The stress patterns of the phrase "black bird" and the compound word "blackbird" differ in that primary stress isplaced on "bird" in the former and "black-" on the latter. These stress differences are correlated with contrasts in meaning, in that listeners interpret the phrase "black bird" as meaning a bird of a particular color, whereas the compound "blackbird" is taken to mean a particular species of bird (Gleitman \& Gleitman, 1970). The stress pattern of "black bird" derives from the nuclear stress rule (NSR) which places stress on the rightmost constituent of a 
phrase (Chomsky \& Halle, 1968; Selkirk, 1984). As such, the stress patterns observed in "black bird" extend beyond noun phrases to encompass verb phrases (e.g., "drank milk"), and whole sentences (e.g., "Jack slept"). The stress pattern of "blackbird" is derived from the compound rule, which assigns stress to the leftmost constituent of the compound (Selkirk, 1984).

The contrasting stress contours of phrases and compounds seem to be correlated with contrasting locations in English verse (Kiparsky, 1975, 1977). Although traditional scansion would treat a phrase like "black bird" as two consecutive stressed syllables, it is clear that they have an iambic contour, with "black" being somewhat weaker than "bird." As a result, "black" should correspond with an expected weak position in a line, with "bird" corresponding with a strong position. Kiparsky (1977) has found that such a pattern is indeed more likely than one in which "black" occupies an expected strong position. Thus, in Shakespeare's works, we find lines like 5a more common than lines like $5 \mathrm{~b}$. The phrase "true rights" occupies WS position rather than SW position, as in the less common "proud foot" in $5 \mathrm{~b}$. Thus even though "true rights" would be scanned as a spondee in 5a, it still has an iambic component to its rhythm, and hence should occupy iambic positions.

(5)a. And your / true rights / be

$\begin{array}{lllll}W & S & W & S & W\end{array}$

termed / a po- / et's rage. S WS W S

(Sonnet 17.11)

b. Lie at / the proud / foot of / a $\begin{array}{lllllll} & \mathbf{S} & \mathbf{W} & \mathbf{S} & \mathrm{W} & \mathbf{S} & \mathrm{W}\end{array}$ con- / queror. S W S

(King John V.vii.113)

With compound words like "heartache" the opposite pattern is found. In the case of such disyllabic compound words, the first syllable occupies strong position, with the second syllable being placed in an expected weak position. Thus, compound words like "heartache" tend to occupy SW rather than WS positions, as shown in 6 . This pattern follows from the compound rule, which assigns stress to the prominent syllable in the leftmost constituent of a compound (Selkirk, 1984).

(6) The heart- / ache, and / the thous-/

W S W S W S
and natu- / ral shocks.
W S W S
(Hamlet, III.i.62)

The relative placement of phrases and compounds in verse created by poets like Shakespeare also appeared in the countingout rhymes. The sample for the NSR analysis consisted of all cases of successive syllables that were considered stressed by the scansion rules, as in "last night," "moon's making," and "two lookers." As can be observed, each of these cases follows the nuclear stress rule in that the primary stress is on the most prominent syllable of the rightmost constituent. For each of these cases, it was determined whether the two stressed syllables occupied WS or SW position in the verse. The position was determined by whether the line containing the phrase was classified as trochaic or iambic (with lines in the "other" category not included). For example, the line $7 \mathrm{a}$ is considered iambic since the final two feet are clear iambs, whereas line $7 \mathrm{~b}$ is considered tro-

\footnotetext{
${ }^{4}$ Analyses involving the nuclear stress and compound rules did not include pseudowords since the former refers to syntactic phrases containing words from identifiable lexical categories and the latter to words that can be decomposed into other actual words. Pseudowords and strings of pseudowords cannot satisfy these criteria. The analysis presented in the section Stress and grammatical category also examined only actual English words.
} 
chaic since its first three feet are trochees. In the iambic line,

\section{(7)a. Two look- / ers and / a switch / about \\ b. Mister / Drum's a / very / good man}

therefore, "two look-" occupies WS position, and its placement agrees with the nuclear stress rule. In the trochaic line, on the other hand, "good man" occupies an SW position, which would not be expected if the nuclear stress rule were operating in the counting-out rhymes. Overall, $61 \%$ (57 of 93) of the items included in this analysis followed the nuclear stress rule, which is significant statistically $(Z=2.02, p<.05) .^{5}$

The compound rule also appeared to influence the location of words in the counting-out rhymes. This analysis consisted of all words that could be construed as compounds. Words were considered compound if they could be divided into components that could stand as free morphs. As in Kiparsky's analysis of English poets, hyphenated words (e.g., "tea-pot") were considered compounds. Only seven such items were found in the survey, but all seven of them followed the compound rule, as in the iambic line 8, where "teapot" occurs in SW position.

(8) Your mo- / ther broke / the tea- / pot lid

In sum, as in the verse of major English poets, the rhythmic structure of countingout rhymes conforms to both the nuclear

\footnotetext{
${ }^{5} \mathrm{~A}$ point needs to be made here about the use of the word "rule" in terms like the nuclear stress rule. Such rules are only one factor operating on word choice and rhythmic structure, and hence one should not expect them to be satisfied $100 \%$ of the time either in formal or counting-out verse. Our weak prediction, which is consistently tested, only claims that they will have some effect beyond chance levels. Our strong prediction, which is harder to test statistically but appears to be supported by the data, is that effects in child and adult verse should be comparable in magnitude.
}

stress and compound rules. Syllable pairs to which the NSR applied tended to occupy a WS position, in accord with the stress contour of such syllable pairs. On the other hand, compound words invariably occupied a SW position, in accord with the greater stress placed on the first syllable of compound words. Although firm conclusions cannot be drawn since only seven compound words were observed in the survey, the compound rule seems to constrain the structure of a line more firmly than does the nuclear stress rule. Kiparsky (1977) found a similar asymmetry in his analysis of formal English poetry. This pattern may be attributable to the fact that the relative stress difference between the syllables in a compound is greater than that between the syllables in a phrase like "black bird." In particular, the weak syllable in "black bird" is much stronger than the weak syllable in "blackbird," as a consequence of which the former may be approximately scanned as a spondee. Such a scansion would be almost unthinkable with the compound word. Thus the pressure against placing the weak syllable of a compound in a strong position should be greater than the pressure against placing the weak syllable of a phrase in a strong position. The former deviations are therefore more rarely observed.

The principle of rhythmic alternation. For almost a century, analyses of rhythmic structure have concluded that people prefer rhythmic patterns consisting of alternating strong and weak beats over other patterns (Sweet, 1975-1976; Bresnan, 1973; Selkirk, 1984). Indeed, this preference is so strong that listeners "hear" an alternating rhythm in specch that objectively lacks such variation (Martin, 1970), and speakers adjust the stress patterns on words in order to establish rhythmic alternation. For instance, when asked to read nonsense words like "pernew," speakers are more likely to place stress on the second syllable in the context of "The big pernew escaped" than 
in the context of "Save the pernew quickly" (Kelly \& Bock, 1988). In the former sentence, placing stress on the first syllable of "pernew" will create a stress clash since "big" will also receive a strong stress. In order to avoid this clash, speakers tend to place stress on the second syllable.

The bias toward rhythmic alternation in both formal and counting-out verse is so strong that statistical confirmation is superfluous. However, finer analyses based on this preference can also be performed. In particular, Selkirk (1984) has argued that the principle of rhythmic alternation resists two consecutive stressed syllables more strongly than two consecutive unstressed syllables. In the latter case, the unstressed syllables are more easily blended together, thus more readily maintaining an equal temporal interval between successive stresses. If such an interpretation is correct, then in English poetry one would expect successive stressed syllables to be rarer than successive unstressed syllables. Some evidence supports this conjecture. In an analysis of middle and modern English verse, Tarlinskaya (1973) found that consecutive weak syllables were more common than successive strong syllables. In Skelton and Lydgate, for example, two weak beats appeared consecutively in $15 \%$ and $19.4 \%$ of the lines sampled from the respective poets. However, consecutive strong beats were found in only $12 \%$ of Skelton's and $11.8 \%$ of Lydgate's lines. If the countingout rhymes also resist consecutive stressed syllables more strongly than successive unstressed syllables, one should find spondees rarer than pyrrhics. Indeed, such a pattern was observed. Whereas spondees appeared in $15.4 \%$ of all lines in the counting-out rhymes (62/403), pyrrhics appeared in a significantly larger $27.8 \%(112 / 403)$ of all lines $(Z=4.37, p<.01)$. In general, then, formal poetry and counting-out rhymes agree in showing greater resistance to successive strong beats than to successive weak beats, as predicted by Selkirk's account of the preference toward rhythmic alternation. $^{6}$

Constraints at foot boundaries. Although stressed syllables of polysyllabic words frequently occupy unstressed locations in English verse, such deviations very rarely cross foot boundaries (Kiparsky, 1977). For instance, in line 9a from Paradise Lost, Milton places the trochaic word, "future," in iambic position. Note, however, that the two consecutive deviant beats occur within a foot. Violations such as $9 b$, drawn from Donne, in which the iambic "himself" occupies the SW position and so crosses a foot boundary, are quite rare in English verse and "simply do not occur in Milton" (Kiparsky, 1977, p. 202).

(9)a. Beyond / all past / examp- / le and / future (P.L. 10.840)

b. Which Him- / self on / those doc- / tors did / bestow. ("Temple," 4)

Foot boundaries thus seem to impose constraints on rhythmic violations in English verse. This pattern suggests that the foot is indeed a psychologically fundamental unit in our poetry. Perhaps the most basic measure in English verse is two beats, the smallest unit that can establish a rhythmic contrast. Still, however, the importance of the foot may be an artifact arising from a particular poetic tradition that arbitrarily gives it a "real" status (Selkirk, 1984). The naturalness of the foot boundary may therefore depend on the poet's tacit, but not necessary, recognition of the foot in his or her writing.

\footnotetext{
${ }^{6}$ These analyses are somewhat flawed in that they are based on the percentage of lines that contain at least one spondee or pyrrhic rather than the percentage of feet characterized by these stress patterns. It is possible that pyrrhics could appear in more lines than spondees while still being less frequently used overall. Perhaps lines very rarely contain more than one pyrrhic foot, whereas multiple spondees appear often in the same line. Although Tarlinskaya does not present her comparisons in terms of feet, we can do such an analysis with the counting-out lines. The basic pattern is replicated as $4.5 \%$ of all feet in the rhymes are spondees, whereas $8.5 \%$ are phyrric $(Z=4.54, p<$ .01).
} 
The question of whether the foot is an arbitrary or natural unit in verse could be addressed more effectively using countingout rhymes, since they are not so firmly entrenched in a formal poetic tradition. The lines in counting-out rhymes can therefore be examined to determine whether rhythmic violations cross the foot boundaries that have been somewhat arbitrarily imposed on them in our scansions. If constraints on rhythmic violations similar to those found for Milton also appear in counting-out rhymes, one might be able to infer that the foot is a psychologically basic rhythmic unit. In order to test this hypothesis, we extracted from the counting-out sample all disyllabic words that occurred in positions that violated their lexical stress patterns (e.g., an SW word in WS position or vice versa). These words were divided into two categories: Those that did not cross foot boundaries, as in example 10a, and those that did, as in $10 \mathrm{~b}$. Although only 13 disyllabic words appeared in positions contradicting their lexical stress patterns (which follows from the monosyllabic constraint discussed below), only two of these violations crossed a foot boundary. The probability that such an asymmetry would be observed by chance given that foot boundaries impose no constraints on line violations is less than .05 .

(10)a. Mister / Macpher- / son, how's / your wife.

b. Leave me / to doub-/ le a / hundred.

Though such results support the view that counting-out rhymes are actually composed of distinct feet which serve to constrain the rhythmic structure of the lines, an alternative explanation remains. In trochaic verse, a disyllabic violation that crosses a foot boundary necessarily must have a trochaic contour. A violation involving an iamb, on the other hand, would necessarily occur within a foot. The opposite pattern holds in iambic verse. In this case, a violation crossing a foot boundary would be iam- bic, whereas a violation that did not cross a foot boundary would be trochaic (see examples $10 \mathrm{a}$ and $10 \mathrm{~b}$ to confirm this). Perhaps the constraint on violations found in English verse, whether Milton's or a child's, derives from an interaction between the basic rhythm of the verse and the stress contour of individual words in the verse. An iambic line might sound far worse if it contained a violation involving an iambic word than if it contained a violation involving a trochaic word. The opposite effects might arise in trochaic verse. In this case, a trochaic violation might damage a line's rhythm more than an iambic violation. Both Kiparsky's analysis of formal English verse and the present analysis of counting-out rhymes face this dilemma. Though the same constraint seems to be operating in both surveys, the unavoidable interdependence between the placement of foot boundaries and the rhythmic structure of the line renders a separation of the two explanations for the constraint impossible at present.

The monosyllabic constraint. When the main stress of a word occupies a weak position in both formal and counting-out verse, the violation very rarely crosses a foot boundary. Nonetheless, violations within a foot are themselves constrained. In particular, Kiparsky (1975) has found that when a strong stress occupies a weak position in English verse, the deviant syllable is almost always a monosyllabic word. Thus, we have lines such as $11 \mathrm{a}$ rather than $11 \mathrm{~b}$ :

\section{(11)a. For the / four winds / blow in / from e- / very coast. (Merchant of Venice I.ii.168) \\ b. For the / four winds / travel / from e- / very coast.}

The fifth syllable location in each line is occupied by a strong stress, though a weak stress would be expected in a canonical iambic line. The difference between the violations concerns whether the strong syllable in the weak position stands alone as a word, as in $11 \mathrm{a}$, or whether it is part of a 
polysyllabic word, as in $11 \mathrm{~b}$. Note that the violation in 11b, "travel," does not cross a foot boundary and so is not subject to the foot boundary constraint. However, when compared with monosyllables, words like "travel" do not have as great a freedom of placement.

To determine whether counting-out verse also follows the monosyllabic constraint, monosyllabic and disyllabic words were surveyed to determine the extent to which they occurred in locations that violated the rhythmic structure of the line. The monosyllabic words consisted of only those items that were considered stressed in the original scansion, since the constraint refers to stressed syllables in unstressed locations. Disyllabic words were used because they could violate the rhythmic structure of a line while still remaining within a single foot. In addition, the survey was restricted to trochaic disyllables in iambic verse. These restrictions were applied because (1) only trochaic words can deviate from iambic rhythm while not violating the foot boundary constraint, and (2) too few iambic words in trochaic verse were encountered to make an analysis of trochaic thythm informative. To ensure that the monosyllabic and disyllabic words were drawn from the same sample of lines, only monosyllabic words found in iambic lines were included.

The analysis compared the percentage of stressed monosyllabic words that occurred in weak position with the percentage of disyllabic trochees whose main stress fell on a weak position. The monosyllabic words occupied a weak position $17 \%$ of the time, whereas only $9 \%$ of the stressed syllables in disyllabic words occupied weak position $(Z$ $=2.01, p<.05$ ). Thus, violations such as 12a were more common than those like $12 \mathrm{~b}$ :

\section{(12)a. To get / some fun / played on /} a drum.

b. A cart / of dross / tumbled / the horse.

Although the third foot in each line opens with a stressed rather than an unstressed syllable, the first violation, "played," is a monosyllable whereas the second, rarer, violation, "tumbled," is a disyllable. The monosyllabic constraint thus appears to apply to counting-out verse as well as formal verse. Together, the foot boundary and monosyllabic constraints create a hierarchy of restrictions on the violations of a line's canonical rhythm, with the foot boundary constraint being stronger than the monosyllabic constraint.

Trochaic and iambic. Thus far, the analyses depend on the accuracy of the distinction between trochaic and iambic lines in the counting-out rhymes. However, this division could be highly arbitrary, the result of an unnatural imposition of an adult's rhythmic categories on a child's verse. In this section, we will attempt to demonstrate that trochaic and iambic do form natural categories in the counting-out rhymes. In particular, the rhythmic patterns of the two classes will be shown to differ systematically and in ways that mirror differences between formal iambic and trochaic verse in English. Three differences between iambic and trochaic counting-out rhymes will be described: (1) the location of inverted feet, (2) the location of pyrrhic feet, and (3) the number of rhythmic violations.

1. Location of inverted feet. Both iambic and trochaic meter in English poetry permit deviations from the prototypical pattern. However, the location of such deviations differs across the two meters. In particular, an inversion in the first foot of a line is more common in iambic verse than in trochaic verse (Newton, 1975). That is, a trochee in the first foot of an iambic line, as in 13a, is relatively more common than an iamb in the first foot of a trochaic line, as in 13b. In an extensive analysis of English poetry, Newton (1975) found that $11.4 \%$ of 2990 iambic lines had trochees in their first foot, whereas only $2.7 \%$ of 5470 trochaic lines had iambs in their first foot. This asymmetry even appeared when comparing iambic and trochaic lines of the same author. For instance, in a sample of Wordsworth's iam- 
bic lines, $8 \%$ contained an initial inversion. However, among a sample of Wordsworth's trochaic lines, only $3 \%$ contained an initial inversion. Similar asymmetries were found for Milton, Shelley, Arnold, Tennyson, Browning, and Keats. No poet in both the iambic and trochaic surveys exhibited the opposite asymmetry. The pattern is thus quite consistent in formal English verse.

(13)a. Reign thou / in hell / thy king- / dom, let / me serve.

(Milton, P.L. VI.183)

b. And lives / wither / as leaves / wither. (Swinburne, "Atalantain Calydon") ${ }^{7}$

If the classification of counting-out rhymes respects a natural division of this verse form into trochaic and iambic, the difference between formal iambic and trochaic meters should also appear in the countingout rhymes. Indeed, such a pattern was observed. Of 157 iambic counting-out lines, 21 , or $13.4 \%$, contained an initial trochee. However, of 247 trochaic counting-out lines, only 4 , or $1.6 \%$ contained an initial iamb $(Z=4.32, p<.01)$. This difference between trochaic and iambic counting-out lines might be due to an overall greater number of trochaic inversions in the iambic lines, rather than some special status of the first foot. This possibility can be tested by looking at the distribution of trochaic inversions across the four feet of the iambic lines. This value can be compared with the distribution of iambic inversions across the four feet of the trochaic lines. Such an analysis continues to support the hypothesis that the first foot of iambic meter is more likely to invert than the first foot of trochaic meter. Of 38 instances in which an iambic foot was scanned SW, 21, or 55\%, occurred in the first foot of the line. On the other hand, only $4 \%$ (4 of 92) of all inversions in trochaic verse occurred in the first foot. This difference between iambic and tro-

\footnotetext{
${ }^{7}$ This line is considered trochaic because it occurs in a poem that has an underlying trochaic rhythm.
}

chaic lines was significant $(Z=6.49, p<$ $.01)$. This evidence is thus consistent with the view that counting-out rhymes do divide into natural categories of iambic and trochaic rhythm.

As one possible explanation for this pattern, consider the type of line produced when iambic meter undergoes initial inversion compared with the type of line produced when trochaic meter undergoes initial inversion. Given that the remaining feet follow canonical patterns, the iambic line, as in $14 \mathrm{a}$, would begin and end with a strong beat whereas the trochaic line, as in $14 \mathrm{~b}$, would begin and end with a weak beat. A general preference might exist for opening and closing a line with strong beats, thus more adequately separating them from preceding and succeeding lines. Given the tendency for unstressed syllables to undergo contraction and enclitization, beginning and ending lines with weak beats would not create very strong line boundaries.

\section{(14)a. Satur- / day's child / is pure / within. \\ b. All good / children / go to / heaven.}

Though no preference judgments can be offered as yet for this claim, some consequences for structural differences between iambic and trochaic verse follow. In particular, just as iambic verse has an idiosyncratic tendency to undergo initial foot inversion in order to open a line with a strong beat, so trochaic verse should have a tendency to undergo final foot inversion in order to close a line with a strong beat. Although we have not noticed this distinction in discussions of iambic and trochaic meter in formal poetry, it does appear quite strongly in counting-out rhymes. Trochaic lines in counting-out verse are far more likely than iambic lines to have a final inversion $(33.3 \%$ compared with $1.9 \%, Z=$ $7.32, p<.01$ ). In addition, of 92 instances in which a trochaic foot was scanned WS, $89 \%$ occurred in the final foot. In iambic verse, on the other hand, only 3 of 38 (8\%) inversions occurred in the final foot. Once 
again, the difference between the iambic and trochaic lines was statistically significant $(Z=8.61, p<.01)$. Thus, a preference exists toward ending a line with a stressed rather than an unstressed beat.

Two final examples of this point may be provided. First, many trochaic countingout lines delete the final, expected weak syllable of the line and so close with a strong beat, as in $15 a-c$.

(15)a. Eenie meenie miny mo

b. Ishka biska tiska too

c. Maggie, Maggie, where is Jiggs

That such lines are fundamentally trochaic with a deleted final syllable rather than iambic with a deleted initial syllable is indicated by (1) the large number of trochaic words in the lines and the marked absence of iambic words, which is a clear sign of trochaic meter in formal verse (Kiparsky, 1975), and (2) the existence of trochaic relatives of the truncated lines with the final weak syllable included, as in "eenie, meenie, minie, moanie." Truncation of final syllables in trochaic lines is also quite common in formal verse, as in the following line from Shelley's "Lines Written on the Euganean Hills":

(16) Noon descends, and after noon. (1. 320)

One last method of encasing lines in strong syllables concerns lines that could not be classified as either iambic or trochaic because they contained an equal number of iambic and trochaic feet. Of 30 lines placed in this category, 13 opened with two feet of one rhythmic type and then closed with two feet of the other rhythmic type, as in example 17. These lines were divided into two classes, those that opened with two trochees and closed with two iambs (as in 13) and those that opened with two iambs and closed with two trochees. In the first case, the line is constructed to open and close with strong beats, whereas in the second case the line opens and closes with weak beats. If a preference exists for bracketing a line with strong beats, then more lines should be found that shift from trochaic to iambic than vice versa. Indeed, in 12 of the 13 cases, the shift was from trochaic to iambic $(p<.02$ by sign test). In addition, the only violation to this principle, "Thirteen, fourteen, maids a'courtin," is not a very strong counterexample. Although the scansion rules placed strong stress on the second syllables of "thirteen" and "fourteen" in accordance with their dictionary entries, it is clear that the contrast between the two words in the line results in first syllable stress for both words. Thus the line is more naturally classed as trochaic. It appears, then, that a bias exists in counting-out rhymes toward marking the beginning and end of lines with strong beats.

(17) Washed his / face in / a fry- / ing pan.

2. Location of pyrrhic feet. A second difference between iambic and trochaic counting-out lines concerns the location of pyrrhic feet. In iambic lines, pyrrhic feet were more likely to occupy the first foot than the fourth foot ( $40 \%$ to $13 \%, Z=3.41, p<$ $.05)$. In trochaic feet, on the other hand, pyrrhics showed a marginally significant tendency to occupy the fourth foot rather than the first foot (38\% to $23 \%, Z=1.68, p$ $<.10)$. These patterns could be explained by the bias toward separating lines with strong beats along with the standard structure of iambic and trochaic lines. Closing an otherwise standard iambic line with a pyrrhic would produce a line that opened and closed with weak beats. However, opening an iambic line with a pyrrhic should be less disturbing since such lines normally begin with weak beats anyway. Hence in iambic verse, pyrrhics should be more strongly resisted in the fourth than the first foot. The opposite pattern is predicted for trochaic lines. If an otherwise standard trochaic line opens with a pyrrhic, the initial strong beat is replaced by a weak beat and the line consequently opens and closes with weak 
beats. Since trochaic lines normally close with weak beats anyway, the presence of a pyrrhic in the final foot should be less damaging. Thus, in trochaic lines, pyrrhics should appear less in the first than in the fourth foot.

3. The tendency to violate. One final difference between iambic and trochaic lines in counting-out verse is the relative tendency for the different meters to contain violations. Iambic feet were more likely to deviate from their canonical rhythm than were trochaic feet. Whereas $26 \%(165 / 628)$ of all iambic feet were occupied by noniambs, only $18 \%(173 / 984)$ of all trochaic feet were occupied by nontrochees $(Z$ $=3.72, p<.05$ ). Though Newton (1975) analyzed his corpus of formal English verse in a slightly different way, it appears that in this case as well, iambic verse is more likely than trochaic verse to deviate from its standard rhythmic format. Though we have no definitive explanation for this difference as yet, it may arise from the fact that English contains far more trochaic disyllabic words than iambic. Kiparsky (1977) has argued that trochaic words in iambic meter shift the line toward a falling, trochaic rhythm. Thus, establishing a strong iambic sound in a line requires the avoidance of trochaic words. However, because of the great preponderance of trochees in English, such systematic avoidance could be extremely difficult to maintain. The use of such trochees might tend to "loosen" the iambic rhythm of a line thus allowing for further deviations. The avoidance of iambs in trochaic verse would be relatively easier and might therefore lead to a "stricter" trochaic line. In fact, though iambic words occur in formal trochaic verse, they are rare, especially when compared with the proportion of trochaic words in iambic verse. ${ }^{8}$

The fact that trochaic counting-out lines contain fewer deviations than iambic lines might be related to functional differences in

\footnotetext{
${ }^{8}$ This explanation was suggested by J. Kathryn Bock.
}

their use. For instance, many of the counting-out rhymes listed in Abrahams and Rankin perform double duty as jump rope rhymes. However, iambic and trochaic lines were not equally likely to be used in jump rope games. In particular, trochaic lines were used as jump rope rhymes more often than iambic lines $(41 \%$ to $30 \%, Z=$ $2.12, p<.05$ ). One possible reason for this difference concerns deviations from the standard rhythmic pattern. If predictability of rhythm helps the child perform well in jump rope games, one might expect the rhymes used in jump rope to have relatively few rhythmic deviations. Rhythmic deviations might be less disruptive to the counting-out ritual, and so would be more tolerated. Of course, such interpretations are highly speculative. Perhaps jump rope rhymes show no difference between trochaic and iambic uses, but trochaic jump rope rhymes are more likely to be confiscated for counting-out rituals. Nonetheless, this difference between counting-out and jump rope rhymes is described because rhymes are an important part of both childhood activities. Given the functional differences between the counting-out and jump rope rituals, an analysis of rhythmic differences between the poetry used in these two domains may be a fruitful way to approach the question of form-function parallels in child verse. Perhaps even in the " $\mathrm{dog}$ gerel" of child verse, some aspects of the function are reflected in the form.

Stress and grammatical category. One problem with the scansion methods used in this paper is that they treat stress as a binary variable consisting of the values stressed and unstressed. Yet, as linguists have pointed out, English speakers can distinguish between more than two levels of stress (Chomsky \& Halle, 1968). For example, the three syllables in "signify" are stressed differently, with primary stress on the first syllable, secondary stress on the third, and tertiary stress on the second. We will now remedy this flaw in our analysis while at the same time examining whether 
children treat stress as dichotomous or multi-leveled.

It seems intuitively clear that monosyllabic words from different grammatical categories differ in stress. Thus, nouns seem to be stressed more strongly than articles, with pronouns in between. If this differentiation extends from speech into poetic structure, one might expect words from different grammatical categories to appear in stressed positions in verse with different frequencies. Kelly and Bock (1988) explored this possibility in formal English verse. They recorded the first 150 monosyllabic instances of the 10 grammatical categories listed in Table 1 from Shakespeare's sonnets and Milton's Paradise Lost. Each word was classified as occurring in a stressed or unstressed location, and the percentage of words occurring in stressed positions was calculated for each grammatical category. Because the results obtained for Shakespeare and Milton correlated very highly, Kelly and Bock combined the percentages for both poets and ranked the grammatical categories according to the frequency with which their instances occupied stressed positions. These rankings are presented in Table 1, and it can be observed

TABLE 1

Percentage of Words in Different Grammatical Categories That Occupied STRESSED POSITIONS IN FORMAL AND COUNTING-OUT VERSE

\begin{tabular}{lcc}
\hline $\begin{array}{c}\text { Grammatical } \\
\text { category }\end{array}$ & $\begin{array}{c}\text { Formal } \\
\text { verse }\end{array}$ & $\begin{array}{c}\text { Counting-out } \\
\text { verse }\end{array}$ \\
\hline Nouns & .94 & .88 \\
Verbs & .76 & .80 \\
Adverbs & .71 & .79 \\
Adjectives & .61 & .61 \\
Modal auxiliaries & .41 & .45 \\
Auxiliaries/copulas & .40 & .37 \\
Pronouns & .34 & .30 \\
Prepositions & .32 & .41 \\
Conjunctions/ & & .19 \\
$\quad$ complementizers & .14 & .09 \\
\hline Articles & .11 & \\
\hline
\end{tabular}

Note. Data for formal verse based on Kelly and Bock (in press). that stress grades fairly continuously through the grammatical categories.

We performed a similar analysis on the counting-out rhymes to determine (1) whether children also treat stress as a continuous rather than binary variable in their verse and (2) whether the relation between stress and grammatical category in child verse is similar to that found in formal verse. We recorded each monosyllabic instance of the grammatical categories listed in Table 1 and classified it as in a stressed or unstressed position in accord with the underlying meter of the line as determined by our scansion techniques. ${ }^{9}$ As with Kelly and Bock's analysis of formal verse, the grammatical categories were ranked according to the frequency with which their instances appeared in stressed positions. The resulting percentages are presented in Table 1 for comparison with the values reported for formal verse. It can be seen that grammatical categories in child verse cannot be classified as simply stressed or unstressed. Rather, as with adult verse, the association between stress and grammatical category gradually changes as one moves from nouns to articles. In addition, it is apparent that the grammatical categories are ordered quite similarly in counting-out and formal verse, which is confirmed by the very high and significant correlation of .98 $(p<.001)$ between the percentages found for the two verse types. This evidence suggests that children not only treat stress in a manner qualitatively similar to that of adults (i.e., continuous or multi-leveled rather than binary), but also quantitatively

\footnotetext{
${ }^{9}$ The location of stressed syllables is confounded with grammatical category because our scansion methods used the latter to determine the former. However, the grammatical category distinctions used in these methods were quite gross, consisting of a stressed set of categories (nouns, verbs, adjectives, and adverbs) and an unstressed set (all other categories). This analysis, on the other hand, searches for finer distinctions among these categories, distinctions that are not captured by the scansion methods used to identify the underlying meters of lines.
} 
in terms of the particular relations between stress and grammatical category.

Summary. For the genre of counting-out rhymes, the following formal poetic principles have been tested and found to operate: The nuclear stress rule $(61 \%)$, the compound rule $(100 \%)$, the greater frequency of pyrrhic feet than spondaic feet ( $28 \%$ vs $15 \%$ ), the tendency for disyllabic feet to fall within foot boundaries when they violate a line's rhythm (85\%), the more frequent appearance in unstressed positions of stressed monosyllabic words rather than the stressed syllables of disyllabic words (17\% vs $9 \%$ ), inverted first feet for iambic meter more than trochaic meter ( $13 \%$ vs $4 \%$ ), inverted final feet for trochaic meter more than iambic meter ( $33 \%$ vs $2 \%$ ), first rather than final foot appearance of pyrrhics in iambic meter ( $40 \%$ vs $13 \%$ ) but final rather than first foot appearance of pyrrhics in trochaic meter ( $38 \%$ vs $23 \%$ ), more violations of iambic than trochaic meter ( $26 \%$ vs $8 \%$ ), and a graduated relation between stress and grammatical category as shown in Table 1. Although these analyses may be criticized individually, the overall similarity between formal and counting-out verse is hard to doubt.

\section{Study 2: Variation in a Single Counting-OUt RHYME}

Given that counting-out rhymes must be preserved through memory, variants of a rhyme should maintain or create poetic patterns that aid this preservation. In order to evaluate this claim, the historical variants of the most common English counting-out rhyme, 18 , were examined. This rhyme is particularly suitable for analysis since its popularity has been long-lasting. Bolton cites it as a favorite of American children in 1888. In addition, the rhyme is amazingly widespread, being used by Englishspeaking children in Great Britain, Australia, and New Zealand. Indeed, it would not be an exaggeration to say that this rhyme is as wide-ranging as English itself.
(18) Eenie, meenie, minie, mo catch a tiger by the toe If he hollers, let him go Eenie, meenie, minie, mo

Given its popularity, it is not surprising that the rhythmic structure of the rhyme is typical of counting-out verse. It consists of strong rhythmic alternation and the trochaic pattern which dominates countingout verse. Although the lines contain seven rather than eight syllables, this pattern allows the lines to begin and end with the preferred strong beats. Given the good metrical qualities of this line, one would not expect much rhythmic deviation, and indeed little is found. Because of its poetic stability, we will discuss historical variants not only in terms of rhythm, but also in terms of other poetic characteristics, such as rhyme and alliteration.

\section{Method}

A total of 95 reports of eenie meenie miney mo were found from the 66 citations provided by Abrahams and Rankin. All 353 lines of these 95 versions were analyzed, whether or not they contained eight syllables. Also, in contrast to the earlier analyses in which each rhyme was distinct, here all versions collected in the literature were analyzed no matter how similar they were to the other versions or to the standard. Thus, whereas Study 1 examined rhyme types while ignoring the tokens within each type, this study examines all of the different tokens of a single rhyme type. The rhythms of these variants were determined using the rules of scansion employed for Study 1.

In comparing versions, differences which appeared to rely on the conventions of reporting rather than actual performance were ignored. In particular, (a) spelling was normalized (e.g., "eeny" and "eenie" were treated as identical); (b) versions in which the first line in $\mathbf{1 8}$ failed to be repeated as the last line were left as is, but the missing last line was not counted as an error; and (c) rhymes added to the end of 18 , 
such as "My mother told me to pick the very best one and you are it" were ignored.

\section{Results and Discussion}

The versions were all quite similar. On the average, three and a half words per version would have to be changed in order to transform it into the standard listed in 18. Such changes from a standard variant are not considered as "corrections," but rather as an objective way of describing the kind and extent of variation that exists. The changes were classified into five categories: (a) replacing part of the first and/or last lines (42\% of all word changes), (b) replacing most of the story line (9\%), (c) changes in the word "hollers" (8\%), (d) miscellaneous changes (16\%), and (e) changes in the word "tiger" (25\%).

Overall, the rhythmic structure of the most common rhyme is typical of the counting-out verse described in Study 1, which included a high proportion of rare rhymes. "Eeny meenie" consists of strong alternation among its variants, with $94 \%$ of the 353 lines using the trochaic pattern which dominates counting-out verse. Most lines (74\%) begin and end with strong beats, which may be why the lines of variant 18 all have seven rather than eight syllables. ${ }^{10}$ The final weak syllable of the last foot of lines one and four are often deleted, as discussed earlier, which allows the trochaic line to end on a stressed syllable. In fact, of the 328 lines that have seven syllables, all end on a strong beat.

The most popular changes to the 166 first and last nonsense lines were "eena deena

\footnotetext{
${ }^{10}$ This value is significantly lowered by the scansion techniques used in the paper. Many lines in the "eeny meeny" corpus begin with "if," which is classified as unstressed according to our criteria. However, the reader's intuitions will verify that this word is indeed relatively stressed in the verse (e.g., "If he hollers let him go"). When "if" is considered stressed, only 2 of the lines do not begin and end with strong stresses: "Be sure you don't let the nigger go" and "I caught a lizard by the toe."
}

dina do" (10 lines), Eny, meny, miny, mo" (9 lines, with the assumption that the transcribers intended " $e$ " and " $i$ " to be short vowels), and "eena, meena, mina, mo" (6 lines). Although different from the standard, these alternatives maintain the rhythmic structure, the rhyme of the first three words, the end rhyme, the alliteration of the last three words, and the front to back vowel progression (e.g., /i/,/ai/,/o/). Only 2 of the 166 lines failed to preserve the SW SW SW S rhythmic structure.

The second of the five categories of changes was due entirely to five versions: changing lines three and four to "Why did you let him go? / Cos he bit my finger so" or "If he hollers daddy-o / Play it cool and let him go" or "If he hollers make him say, I surrender U.S.A.;" changing line two to "Mary had a little lamb" and changing line three to "Be sure you don't let the nigger go." The versions that produced the last two changes also used a jumbled line order. Instead of the nonsense lines being placed in positions one and four, they were located in positions two and four, and one and three in the two versions, respectively. Although quite different from the standard version in terms of lexical content, these alternatives generally preserve rhythmic alternation and four beats per line, as well as the /o/ end rhyme of the standard version.

The third category consists of 14 instances of "squeals," 5 of "holler," 2 of "screams," and 1 each of "cries," "quarrels," "chatters," "hollows," and "roars." The most popular of these alternatives, "squeals," has less alliteration and one less syllable (though this depends on the pronunciation) than "hollers," though it has assonance with "eeny meeny." This weakening of the poetic structure possibly derives from the infrequent use of "hollers" in some English dialects. All 14 versions using "squeals" come from New Zealand or Great Britain.

The fourth, or miscellaneous, category consisted of 15 versions that used "his" in- 
stead of "the," 8 that used "when" instead of "if," 5 that used "it" instead of "him," 3 that used "the" instead of " $a$, " 2 that used "thumb, send him hum" (i.e., "home") and "mum" instead of "toe, let him go" and "mo," 2 that used "caught" instead of "catch," and 16 other word changes that occurred only once each. The changes generally preserve meaning and occur in function words. The changes also preserve rhythmic structure because in most cases monosyllabic unstressed words replace one another and monosyllabic stressed words replace one another.

The fifth category is, in many ways, the most interesting. A total of 59 "niggers," 11 "tigers" (the object caught in today's American standard version), 3 "neighbors," 2 "monkeys," 2 "lions," 2 "babies," and one each of the following are caught by the toe: "baby," "beatnik," "beggar," "blank," "chicken," "feller," " "jap," "lamb," "lizard," "pig," "rabbit," "robber," "rooster," and "schmoo." The variation in what is caught is recent, beginning around World War II and continuing in the printed collections through Abrahams and Rankins' (1980) dictionary. Cultural changes from outside the tradition made "nigger" unacceptable, producing a naturally occurring test of the effects of meaning and poetic constraints on recall and, in this case, on the generation of new alternatives. Adults may have introduced some of the alternatives into the literature, either by suggesting them to children or in the course of editing manuscripts for publication, but the children nonetheless had to choose from among the alternatives, an observation that becomes important when we examine the current state of the rhyme.

If "nigger" was not an acceptable word, what could replace it? Unless a whole line or two changed, an animate object with toes was required in order to preserve meaning. If hooves count as toes to children, then this constraint was satisfied in all cases. Attention to poetics further reduced the possible substitutions. All but three responses were disyllabic trochaic words preserving the rhythmic structure. The substituted word could be better poetically than the original, though less emotional, if it had rhyme, alliteration, and/or assonance. Two of the three most popular substitutes, "tiger" and "monkey," account for $42 \%$ of the substitutions. "Tiger" alliterates with "toe" and has assonance with "miney," and "monkey" alliterates with "meenie," "miney," and "mo" and rhymes with "eenie," "meenie," and "miney." Once children hit upon these two replacements for "nigger," the variation in the rhyme dropped considerably. Collections obtained recently from Duke undergraduates and five to nine year old children show "tiger" to be the clear favorite followed by "monkey" (Rubin, 1986). These two words account for nearly all the current variability in the second line of 18 . Thus the rhyme has reached or is reaching a new period of stability, a stability founded upon good poetics created by the recent revisions.

In sum, variations in memory, geographical location, and time period lead to natural alterations in counting-out rhymes. Nonetheless, these alternants are clearly constrained by poetic factors, such as preferences for lines that contain rhyme, alliteration, alternating beats, as well as more specific factors, such a trochaic rhythm and lines bracketed with strong beats. When coupled with the even more detailed rhythmic restrictions found in historically less related counting-out rhymes, it appears that counting-out verse is governed by a set of complex structural rules, rules which, like those used by Shakespeare and Milton, allow for a good deal of interesting variability, but also create a clearly recognizable genre.

\section{General Discussion}

This paper discusses a number of similarities between the rhythmic structure of for- 
mal English verse and the rhythmic structure of counting-out rhymes used by children. Given the unusual characteristics of counting-out rhymes that were described in the introduction, the fact that their rhythmic structure conforms to the structure of formal verse suggests that natural and basic principles underlying English rhythm are being uncovered. However, when one claims that a certain rhythmic pattern in verse is "naturally" preferred rather than an artificial convention, what is meant by "naturally"? We assume that rhythmic patterns in verse are "natural" if they parallel similar patterns found in ordinary speech. Thus, the relevance of the nuclear stress rule in verse is "natural" because the rule governs nonpoetic language as well. This assumption provides a useful heuristic for gaining a better understanding of the rhythmic structure of poetry, ordinary speech, and the acquisition of prosodic rules. We will discuss each of these areas briefly.

As Kiparsky (1975) has pointed out, our understanding of the rhythmic structure of poetry is quite impoverished, particularly when compared with our understanding of rhythm in music. One reason for this relative ignorance could be the lack of specific hypotheses about what rules might affect verse rhythm. A potentially powerful way to provide such hypotheses could draw upon the factors that affect rhythm in everyday speech and examine whether they also affect poetic rhythm. This paper, as well as Kiparskys' (1975, 1977), takes such an approach by examining whether wellknown stress rules operate in verse in addition to "prosaic"' speech. As another example, consider recent work by Fowler and Housum (1987), which reports that the first occurrence of a word in speech (corresponding with new information) receives more stress than the second occurrence of a word (corresponding with given information). If a correlation between givenness and stress operates in verse as well as ordinary speech, one might expect that later repeti- tions of a word referring to a particular object would occur more often in unstressed positions than would the initial usages of the word. For example, consider the following famous lines from Byron's Childe Harold's Pilgrimage:

(19) While stands the coliseum, Rome shall stand,

When falls the coliseum, Rome shall fall,

And when Rome falls, the world.

The first two instances of "Rome" occur in stressed positions, whereas the final mention, corresponding with greater givenness, occurs in an unstressed position. If substantiated, such an analysis provides one satisfying reason for the appearance of normally stressed words, such as nouns, in unstressed positions. At present, we have little more to say than that they are "accidents," or, perhaps, "bad poetry." However, explanations such as that above might enhance both our understanding and appreciation of poetic structure and how it relates to prose. In addition, unlike the nuclear stress and compound rules, the givennew distinction derives from pragmatic considerations. This fact could lead to testable speculations about which types of poetic language might be most sensitive to the prosodic correlates of given and new information (e.g., dramatic versus lyric). In general, a potentially powerful heuristic for enriching our understanding of verse is provided by the assumption that the rhythmic structure of verse reflects that of prose. It could (gasp!) inspire psycholinguists to moonlight as literary critics.

In addition to discovering aspects of poetic rhythm by analogy with normal speech rhythm, one might also move in the reverse direction and use knowledge of poetic rhythm to explore speech rhythm. For instance, the clear pattern of alternations between strong and weak beats in verse led Sweet (1875-1976) to speculate that this 
preference for rhythmic alternation operated in speech and other rhythmic activities. Today, many linguists claim that this pattern is THE basic metrical preference in English and other languages and has been used to account for distributions of stresses on words (Selkirk, 1984), syllable lengthening in speech (Fowler, 1977), and changes in word stress over time (Kelly, in press; Kelly \& Bock, 1988). Some of the rhythmic patterns discussed in this paper have yet to be explored in ordinary speech, but precedent indicates that attention to verse structure can help us understand rhythm in general. In addition, the use of verse is one of the few means we have to study the rhythmic rules used by speakers who lived in periods prior to the existence of audio recording. To the extent that correlations between verse rhythm and speech rhythm are documented, we can with greater confidence use poetic rhythm to make inferences about the speech of earlier historical periods.

This final point applies as well to studies of a child's acquisition of prosodic rules. Given limitations in our present understanding of the acoustic correlates of stress and rhythm (Levelt, in press), the availability of child verse provides a valuable resource for exploring the development of prosody. This paper provides an initial example of the potential usefulness of this material as we have shown that the rhythmic structure of counting-out rhymes exhibits a surprising richness, a richness that parallels to some extent the rules governing formal English verse and adult speech. Thus, these analyses indicate that young children have acquired stress rules that depend on knowledge of phrase (the nuclear stress rule) and lexical (the compound rule) structure. In addition, our focus on counting-out rhymes provides one attempt to tie together basic research in psycholinguistics with language creativity, which demonstrates, perhaps, the tractability of this intriguing topic to current cognitive psychology.

\section{Appendix A}

In order to explore the orthographic relatedness between rhyme words, the two most frequent rhymes in counting-out verse were examined. These were $/ \mathrm{i} /$ as in "me" and "tea" and $/ \mathrm{u} / \mathrm{as}$ in "you" and "blue." All end rhymes were recorded from the Abrahams and Rankins collection as long as the rhymes were in adjacent lines. Given that priming effects diminish with the separation between the relevant items, restricting the sample to rhymes as near to one another as possible seemed most likely to uncover any orthographic similarities between rhymes. The sample was also restricted to monosyllabic rhymes, since these are by far the most typical, and rhymes involving nonsense words were not included since they lack an established spelling. A sample of rhymes from formal verse was obtained from Bartlett's Familiar Quotations (1980). All /i/ and /u/ rhymes were recorded under the same restrictions governing the counting-out sample. However, no nonsense words were present in the formal sample, hence the last restriction on the counting-out sample was irrelevant here.

Four pairs of rhyme columns were created by crossing the factors of rhyme source (counting-out vs formal verse) and vowel in the rhyme (/i/ vs /u/). The rhymes in each pair were arranged in two columns, with column one listing the first rhyme word listed in the poem and column two listing the second rhyme in the poem. For each pair of columns, five random pairings of the words from column one with those from column two were performed and the percentage of orthographic matches (e.g., "see" and "free") calculated. The mean value across the five pairings was then used as the estimate of the percentage of orthographic matches expected by chance. These estimates for each of the four rhyme types (e.g., counting-out verse with /i/ rhymes) were compared statistically with 
the actual percentage of matches to determine whether the latter was more or less than would be expected by chance. This procedure is basically identical to that used by Dell and Reich (1981) to determine whether certain structural patterns observed in naturally produced speech errors occurred with greater than chance frequency. Within formal verse, the percentages of orthographic rhyme matches expected by chance was estimated at $16 \%$ for $/ \mathrm{u} /$ and $38 \%$ for $/ \mathrm{i} /$. However, the actual percentage of orthographic matches was significantly greater than these chance estimates, being $33 \%(13 / 39)$ for $/ u /$ rhymes $(Z=2.68$, $p<.01)$ and $48 \%(58 / 121)$ for $/ \mathrm{i} /$ rhymes $(Z$ $=2.17, p<.05$ ). Within the counting-out rhymes, the percentage of orthographic matches expected by chance was $16 \%$ for $\mathrm{l} / \mathrm{/}$ and $28 \%$ for $/ \mathrm{i} /$. The actual percentage of matches did not differ significantly from chance, being $12 \%(3 / 25)$ for $/ \mathrm{u} /(Z=$ $-0.27, p>.30)$ and $26 \%(14 / 54)$ for $/ \mathrm{i} /(Z=$ $-0.18, p>.30)$. These differences between formal and counting-out verse are consistent with (1) adults possessing greater knowledge of orthography than children and (2) children creating counting-out verse with little influence from adults.

\section{REFERENCES}

Abrahams, R. D., \& Rankin, L. (1980). Countingout rhymes: A dictionary. Austin, TX: University of Texas Press.

ARnheIm, R. (1974). Art and visual perception. Berkeley, CA: University of California Press.

Bartlett, F. C. (1932). Remembering. Cambridge: Cambridge University Press.

Bartletr, J. (1980). Familiar quotations (15th ed.). Boston, MA: Little, Brown.

Bolton, H. C. (1888). The counting-out rhymes of children. New York: Appleton.

Brown, R. (1973). A first language: The early stages. Cambridge, MA: Harvard University Press.

BuRLING, R. (1966). The metrics of children's verse: A cross-linguistic study. American Anthropologist, 68, 1418-1441.

Chomsky, N., \& Halle, M. (1968). The sound pattern of English. New York: Harper \& Row.

Dell, G. S., \& REICH, P. A. (1981). Stages in sentence production: An analysis of speech error data. Journal of Verbal Learning and Verbal Behavior, 20, 611-629.

FowleR, C. A. (1977). Timing control in speech production. Bloomington, IN: Indiana University Linguistics Club.

Fowler, C. A., \& Housum, J. (1987). Talkers signaling of "new" and "old" words in speech and listeners' perception and use of the distinction. Journal of Memory and Language, 26, 489-504.

Gleitman, L. R., \& Gleitman, H. (1970). Phrase and paraphrase. New York: Norton.

Gleitman, L. R., AND WanNer, E. (1982). Language acquisition: The state of the state of the art. In $\mathrm{E}$. Wanner and L. Gleitman (Eds.), Language acquisition: The state of the art. New York: Cambridge University Press.

Gombrich, E. H. (1961). Art and illusion. Princeton, NJ: Princeton University Press.

HALle, M., \& KeYser, S. J. (1971). English stress: Its form, its growth, and its role in verse. New York: Harper \& Row.

Hirsh-Pasek, K., Kemler-Nelson, D. G., Jusczyk, P. W., Wright, K., Druss, B., \& Kennedy, L. (1987). Clauses are perceptual units for young infants. Cognition 26, 269-286.

KELLY, M. H. (in press). Rhythmic alternation and lexical stress differences in English. Cognition.

KelLY, M. H., \& BoCK, J. K. (1988). Stress in time. Journal of Experimental Psychology: Human Perception and Performance, 14, 389-403.

KiPARSKy, P. (1975). Stress, syntax, and meter. Language, 51, 576-616.

KIPARSKY, P. (1977). The rhythmic structure of English verse. Linguistic Inquiry, 8, 189-247.

KÖHLER, W. (1947). Gestalt psychology. New York: Liveright.

Levelt, W. J. M. (in press). Speaking: From intention to articulation. Cambridge, MA: MIT Press.

LORD, A. B. (1960). The singer of tales. Cambridge, MA: Harvard University Press.

Martin, J. G. (1970). Rhythm-induced judgments of word stress in sentences. Journal of Verbal Learning and Verbal Behavior, 9, 627-633.

Miller, W., \& ERvin, S. (1964). The development of grammar in child language. In U. Bellugi and $R$. Brown (Eds.), The acquisition of language (pp. 9-34). Monographs of the Society for Research in Child Development Vol. 29 (1, Serial No. 92).

Newton, R. P. (1975). Trochaic and iambic. Language and Style, 8, 127-156.

OPIE, I., \& OPIE, P. (1959). The lore and language of schoolchildren. London: Oxford University Press.

Rubin, D. C. (1986). Memory traditions: The cognitive psychology of counting-out rhymes, ballad, and epic. Unpublished manuscript.

Seidenberg, M. S., \& Tannenhaus, M. K. (1979). Orthographic effects on rhyme monitoring. Jour- 
nal of Experimental Psychology: Human Learning and Memory, 5, 546-554.

SELKIRK, E. O. (1984). Phonology and syntax: The relation between sound and structure. Cambridge, MA: MIT Press.

ShapiRo, K., AND Beum, R. (1965). A prosody handbook. New York: Harper \& Row.

SMITH, B. H. (1968). Poetic closure. Chicago, IL: University of Chicago Press.

SWEET, H. (1875-1976). Words, logic, and grammar.
Transactions of the Philogical Society, 1875-1876, 470-503.

TARLINSKAYA, M. (1973). The syllabic structure and meter of English verse from the Thirteenth through the Nineteenth Century. Language and Style, 6, 249-272.

Webster's new collegiate dictionary. (1977). Springfield, MA: Merriam-Webster.

(Received September 28, 1987)

(Revision received June 21, 1988)

Statement of awnership, management, and circulation required by the Act of October 23, 1962, Section 4369, Title 39, Unlied Stares Code: of

$$
\text { JOURNAL OF MEMORY AND LANGUAGE }
$$

Published bimonthly by Academic Press, Inc., I East First Street, Duluth, MN 5580z. Number of issues published annually: Adam Just and Prof. Patricia A. Carpenter, Department of Psychology, Carnegie-Melion

Owned by Acadernic Press, Inc., 1250 Sixth Avenue, San Diego, CA 9210I. Known bondholders, mortgagees, and other security hojders owning or holding I percent or more of total amount of bonds, mortgages, and other securities: None. Paragraphs 2 and 3 include, in cases where the stockholder or security holder appears upon the books of the company as
trustee or in any other fiduciary relation, the name of the person or corporation for whom such trustee is acting, also the statements in the two paragraphs show the at fiant's full knowledge and belief as to the circurnstances and conditions under which stockholders and security holders who do hot appear upon the books of the company as trustees, hold stock and securities in a capacity other than that nt a bmona fide nwher. Names and addresses of individuals who are stockholders corporation have been included in paragraphs 2 and 3 when the interests of such indjviduals are equivalent to 1 percent or

Total no. copjes printed: average no. copies each issue during preceding 12 months: 2429; single issue nearest to filing date: 2353. Pald circulation (a) to term subscribers by mall, cartier delivery, or by other means: average no. copies each issuc during preceding 12 manths: (1980; single issue nearest to filing date: . distribution by mail, carrier delivery, or by other means: averape no copies each issue during preceding 12 months: 69 , single issue nearest to filing dare: 69 . Total no. of copies distributed: average no. copies each issue during preceding 12 months: 2049; single issue nearest to filing date: 2030 . 